\title{
Virtual Reality Flexible Sigmoidoscopy Simulator Training: Impact on Resident Performance
}

\author{
Michael L. Tuggy, MD
}

Background: Flexible sigmoidoscopy, a core skill for the primary care physician, requires learned hand-eye skills that can be difficult to master during residency training. With recent advances in virtual reality simulation technology, simulated flexible sigmoidoscopes are available to family medicine residents for training before their initial and subsequent live patient examinations. The purpose of the study was to determine whether a virtual reality flexible sigmoidoscope simulator would improve the hand-eye skills and various performance parameters in a live patient.

Methods: Residents were assigned to a control $(n=5)$ or experimental group $(n=5)$ in which the experimental group trained on a virtual reality sigmoidoscopy simulator before their first sigmoidoscopies on live patient volunteers. After the initial live patient sigmoidoscopies, both control and experimental groups trained on the simulator so that it was possible to evaluate presimulator and postsimulator training effects on live patient performance and to compare speed and skill between the groups at different levels of training.

Results: Training on the virtual reality simulator produced substantial improvements in examination times and hand-eye skill measures. After 6 to 10 hours of training on the simulator, the experimental group achieved significantly faster insertion times to $30 \mathrm{~cm}(119$ versus $357 \mathrm{sec}, P=0.03), 40 \mathrm{~cm}(211$ versus 518 $\sec , P=0.03$ ), and a shorter mean length of examination ( 323 versus $654 \mathrm{sec}, P=0.01$ ). There was also significant improvement of hand-eye skill measures of the experimental group in directional errors (1.6 versus. 8.6, $P<0.01$ ), percentage of colon visualized ( 79 versus 45 percent, $P=0.02$ ), and viewing quality of examination when compared with the control group's initial performance on live patients. Resident survey findings after the study confirmed the trainee's perception of the benefit of the simulator training.

Conclusions: This study shows the value of virtual reality simulator training for accelerating the development of the hand-eye skills to perform adequate sigmoidoscopy. (J Am Board Fam Pract 1998;11:426-33.)

Flexible sigmoidoscopy is a commonly taught procedure in most family practice and internal medicine residency training programs. Family physicians have found flexible sigmoidoscopy to be an important screening and diagnostic tool in their practices for the past 2 decades. ${ }^{1-3}$ The training programs used in the past have relied primarily on the resident gaining experience on live patients with supervision from an experienced endoscopist. 4,5 Residency programs use various methods to introduce their residents to flexible sigmoidoscopy, including didactics, one-on-one training sessions with rubberized colon models, and slides

Submitted, revised, 17 April 1998.

From the Swedish Family Medicine Residency, Seattle. Address reprint requests to Michael L. Tuggy, MD, Swedish Family Medicine Residency, 1401 Madison, Suite 100, Seattle, WA 98104.

This study was funded by a donation from Interact Medical, Inc, to reimburse the patient volunteers for participation in the study. No other reimbursements were made to either the trainees or the investigator in this study.

Presented at the 1998 AAFP Scientific Assembly Research Competition, San Francisco, 18 Sept 1998. of pathologic lesions. There has been no uniform standard for training adopted by residency programs, and many residents receive highly variable exposure to sigmoidoscopy within their own programs. Professional family practice organizations, such as the American Academy of Family Physicians, have strongly encouraged flexible sigmoidoscopy training during and beyond residency to promote higher rates of colon cancer screening and detection among patients.

Several drawbacks to this system of training affect the patients, the trainee, and the supervising physician. Individual physicians bring with them a wide range of hand-eye and spatial skills that often lead to variable learning curves when acquiring sigmoidoscopy skills. The trainee is frequently anxious about performing the examination and concerned about causing pain or injury to the patient. The patients are subjected to sigmoidoscopy by an inexperienced examiner, which can not only be disconcerting to them but also deter follow-up examinations. Finally, the supervising physician must 
instruct the trainee with the patient fully aware of the training session during their examination.

The time and number of examinations required for a physician to become competent to perform an examination independently vary widely. ${ }^{6}$ Some residents achieve competency after 15 to 20 procedures, whereas others might require more than can be performed during residency training. ${ }^{7-9}$ All these factors plague the current training paradigm.

The rapid advance of computer technology has allowed for the creation of virtual reality training devices. Virtual reality simulation recreates the features of a live examination in several ways ${ }^{10}$ : it has high-resolution graphics that resemble the target organ or object, the organs are deformable and respond to changes that the trainee causes (ie, straightening the colon during an examination), the simulation reacts physiologically (peristalsis and breathing movements) and responds to the operator's actions (bleeding after biopsy), and the virtual reality device provides the trainee with force feedback. Force feedback is a key feature in realism, because it teaches the trainee the tactile responses they will need to react appropriately when examining a live patient. ${ }^{10,11}$

The anatomic models available for training residents usually consist of rubber mock colons with multiple lesions placed inside the colon tube. The models are not dynamic, they do not replicate the variability seen in patients, and they do not feed back to the examiner the discomfort experienced by the patient. Residents rarely practice on such models because they lack realistic simulation. Furthermore, there is no mechanism to assess the resident's ability to recognize pathologic lesions or perform biopsies, and there is no way to analyze the trainee's performance. In contrast, a virtual reality simulator can provide all of these features in an environment that does not require constant feedback from or supervision by a trained endoscopist.

Several articles have described the uses of virtual reality simulator technology for cholecystectomy, laparoscopic surgery, arthroscopy, and anesthesiology ${ }^{10-12}$ and have reviewed the potential for surgical and patient simulation, but no studies have been published establishing improved performance on live patients after training. The promise of these virtual reality simulators appears to be great, especially for training programs hoping to prepare physicians for practice in an increasingly competitive medical marketplace, yet the actual impact on performance with live patients has never been proved.

The purpose of this study was to determine what effects a flexible sigmoidoscopy simulator would have on residents' learning hand-eye skills needed for sigmoidoscopy and on how well they performed initial live patient sigmoidoscopies. The parameters measured included performance times of various segments of the examination, specific hand-eye skills, and patient perceptions. The residents' subjective impression of the ability of the simulator to help them learn the hand-eye skills needed for performance of the procedure was also elicited.

\section{Methods}

Ten residents in the Swedish Family Medicine Residency Program in Seattle, with no experience in flexible sigmoidoscopy, volunteered to be study participants for training on the virtual reality simulator. The volunteers were randomly assigned to an experimental $(n=5)$ and a matched control $(n=$ 5) group. The control group had no training or preparation before performing their first live patient examination, whereas the experimental group spent 5 hours training on the Gastro-Sim ${ }^{\circledR}$ flexible sigmoidoscopy simulator built by Interact Medical. ${ }^{13}$ The experimental group was not given any training or guidance on the skills required for sigmoidoscopy other than what was encountered during the simulation.

Examinations were performed on two live patient volunteers. The volunteers were healthy men aged between 25 and 35 years who gave informed consent regarding the risks of the study and who were compensated for their participation in the study. Before the examinations the residents read a prepared script stating the objectives of their live patient examinations and requesting that they not reveal to which arm of the study they were assigned. Before each set of sigmoidoscopies, each patient received a brief examination by the supervising physician to ensure the colon was adequately prepared. All air was then removed from the colon before the study participants performed their examinations.

Each matched pair of residents then performed examinations sequentially on the same patient to reduce the risk of encountering different colon structures, which could affect their performance. 


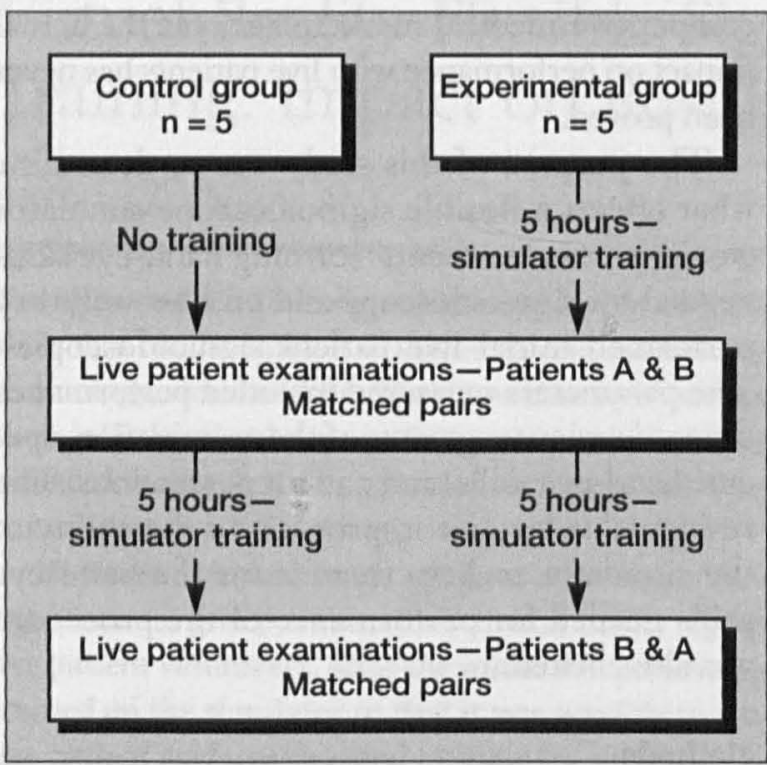

Figure 1. Study design for virtual reality flexible sigmoidoscopy study.

An experienced sigmoidoscopist monitored the examinations. As an added safety feature, the supervising sigmoidoscopist, at the command of the resident, inserted or retracted the sigmoidoscope. This assistance allowed the trainee to perform all steering and torque maneuvers and reduced the risk of injury by excessive pressure of insertion.

The examinations were videotaped, and observations were made on time to reach $30 \mathrm{~cm}, 40 \mathrm{~cm}$, and maximal insertion. Total time of examination, total time in red-out (the view totally obscured by the colon wall) quality of visualization of the colon walls, and an estimated percentage of the colon visualized were ascertained from the videotaped examinations. Hand-eye skills were assessed by the amount of directional errors that were made during the examination. Directional errors were defined as the inability of the examiner to direct the sigmoidoscope correctly toward the lumen when it was visualized. The patients completed a pain scale, rated the perceived confidence of the examiner, and evaluated the duration of the examination. The patient was blinded to the experience of the examiner and to which arm of the study the trainee was assigned.

After the first set of live patient examinations, each of the five residents in the control group was then allowed access to the simulator and completed 5 hours of training. The experimental group continued to train on the simulator for up to 5 additional hours. Once this training was completed, the matched resident pairs again performed the procedure on the volunteer patients. During this second phase of the trial, the paired residents examined the alternate patient (Figure 1).

The performance data were analyzed by comparing the control and experimental groups at each phase of the training sequence to determine whether there were significant differences between the two groups. The initial performance of the control residents on the live patient was compared with their performance after 5 hours of training on the simulator, and the live patient performance data of the control and experimental groups were compared after each had had 5 hours of simulator training to determine any significant differences in their skills. The paired t-test was used to compare the differences between the mean scores of the two groups at the designated points in the study protocol. The degree to which the trainee was able to perform a 360-degree viewing of the colon wall on exiting the live patient was assessed on the videotape. Each examination was rated as organized, adequate (moderately organized), or haphazard, based on the videotape of the sigmoidoscopic examination. The Mann-Whitney U-test was used to analyze the qualitative assessment of colon viewing.

At the conclusion of the study, the resident trainees completed an anonymous survey commenting on the effect of the simulator on their perception of their hand-eye skills. They also rated selected features of the simulator as well as their confidence in performing the procedure and were asked what effect simulator training would have on their likelihood of performing sigmoidoscopy in their own practice.

\section{Results}

The results of the study show a clear improvement in the performance of the trainees who had used the Gastro-Sim sigmoidoscopy simulator (Table 1). During the initial sigmoidoscopy examinations on the live patients after 5 hours of simulator training, the experimental group had a substantial but not statistically significant reduction in insertion speeds at every measured level and a reduced total time of examination. Virtual reality training was associated with significantly fewer errors in directional movement of the sigmoidoscope and improved quality of viewing the colon surface. The amount of time the trainees spent with the sigmoi- 
Table 1. Performance Comparisons and Quality of 360-degree Visualization Technique Between Control and Experimental Groups.

\begin{tabular}{|c|c|c|c|c|}
\hline Parameter Measured & $\begin{array}{c}\text { Control vs } \\
\text { Experimental } \\
\text { With 5-h Training }\end{array}$ & $\begin{array}{l}\text { Control vs } \\
\text { Experimental With } \\
\text { 6- to 10-h Training }\end{array}$ & $\begin{array}{l}\text { Control vs } \\
\text { Control With } \\
\text { 5-h Training }\end{array}$ & $\begin{array}{l}\text { Control With 5-h } \\
\text { vs Experimental } \\
\text { With 5-h Training }\end{array}$ \\
\hline Time to $30 \mathrm{~cm}(\mathrm{sec})$ & $\begin{array}{l}357 \text { vs } 286 \\
(P=0.52)\end{array}$ & $\begin{array}{l}357 \text { vs } 119 \\
(P=0.03)^{*}\end{array}$ & $\begin{array}{c}357 \text { vs } 175 \\
(P=0.07)\end{array}$ & $\begin{array}{c}175 \text { vs } 286 \\
(P=0.12)\end{array}$ \\
\hline Time to $40 \mathrm{~cm}$ (sec) & $\begin{array}{c}518 \text { vs } 341 \\
(P=0.27)\end{array}$ & $\begin{array}{l}518 \text { vs } 211 \\
(P=0.03)^{\star}\end{array}$ & $\begin{array}{c}518 \text { vs } 279 \\
(P=0.07)\end{array}$ & $\begin{array}{c}279 \text { vs } 341 \\
(P=0.52)\end{array}$ \\
\hline Total examination time (sec) & $\begin{array}{c}654 \text { vs } 530 \\
(P=0.31)\end{array}$ & $\begin{array}{l}654 \text { vs } 323 \\
(P=0.01)^{*}\end{array}$ & $\begin{array}{l}654 \text { vs } 372 \\
(P=0.02)^{\star}\end{array}$ & $\begin{array}{c}372 \text { vs } 530 \\
(P=0.07)\end{array}$ \\
\hline Directional errors (n) & $\begin{array}{c}8.6 \text { vs } 2.8 \\
(P=0.01)^{*}\end{array}$ & $\begin{array}{c}8.6 \text { vs } 1.6 \\
(P<0.01)^{*}\end{array}$ & $\begin{array}{l}8.6 \text { vs } 2.4 \\
(P<0.01)^{*}\end{array}$ & $\begin{array}{c}2.8 \text { ys } 2.4 \\
(P=0.67)\end{array}$ \\
\hline Time in red-out (sec) & $\begin{array}{c}70 \text { vs } 27 \\
(P=0.16)\end{array}$ & $\begin{array}{c}70 \text { vs } 14 \\
(P=0.07)\end{array}$ & $\begin{array}{c}70 \text { vs } 20 \\
(P=0.10)\end{array}$ & $\begin{array}{c}27 \text { vs } 20 \\
(P=0.49)\end{array}$ \\
\hline Percentage of colon visualized & $\begin{array}{c}45 \text { vs } 55 \\
(P=0.60)\end{array}$ & $\begin{array}{c}45 \text { vs } 79 \\
(P=0.02)^{\star}\end{array}$ & $\begin{array}{c}45 \text { vs } 68 \\
(P=0.09)\end{array}$ & $\begin{array}{c}68 \text { vs } 55 \\
(P=0.48)\end{array}$ \\
\hline Quality of viewing $360^{\circ} \dagger$ & $\begin{array}{c}2.4 \text { vs } 1.3 \\
(P=0.05)^{\star}\end{array}$ & $\begin{array}{c}2.4 \text { vs } 1.4 \\
(P=0.03)^{\star}\end{array}$ & $\begin{array}{c}2.4 \text { vs } 1.6 \\
(P=0.058)\end{array}$ & $\begin{array}{l}1.6 \text { vs } 1.3 \\
(P=0.49)\end{array}$ \\
\hline
\end{tabular}

"Statistically significant difference.

†Based on a rating scale of 1 - organized, 2 - adequate, 3 - haphazard.

doscope in red-out, and the percentage of the colon visualized was improved. There was no difference between the groups in pain scores, level of confidence, or perceived duration of examination by the patients. After additional training ( 6 to 10 hours), the experimental group was able to perform significantly better than the baseline control group in six of seven parameters measured.

After the second phase of the trial, comparisons between the control group before and after training on the simulator showed greater reductions in insertion speeds and a significant reduction in the duration of the examination, increased quality of viewing, and fewer directional errors. There was no significant difference in the percentage of the colon visualized or the time in redout, though their skills in dealing with these areas were improved.

The second phase also allowed us to compare the performance of the control and experimental groups after each group had had 5 hours of simulator training. The control group performed only slightly better than the experimental group when the simulator training time was equivalent (Table 1 ), which suggests that the randomization process did not favor the experimental group in phase 1 of the trial. Performance measures between the experimental group after 5 hours of training and after 6 to 10 hours of training reflected a modest improvement in the performance criteria, but the only significant change was the total time of ex- amination (Table 2). Variation in performance times with further training decreased substantially, suggesting that simulator training allowed those residents who had more difficulty with hand-eye skills to catch up with their more skilled peers. The final comparison was between the experimental and control groups at the end of the entire study (6 to 10 hours of training and 5 hours of training, respectively).

Simulator-use logs during the second phase of the trial showed that those residents in the experimental group who had more difficulty during the first phase of the trial returned to the simulator for

Table 2. Performance Comparisons at End of Study.

\begin{tabular}{|c|c|c|}
\hline $\begin{array}{l}\text { Parameter } \\
\text { Measured }\end{array}$ & $\begin{array}{l}\text { xperimental With 5-h } \\
\text { vs Experimental With } \\
\text { 6- to 10-h Training }\end{array}$ & $\begin{array}{l}\text { Control With 5-h } \\
\text { vs Experimental With } \\
\text { 6- to 10-h Training }\end{array}$ \\
\hline $\begin{array}{l}\text { Time to } 30 \mathrm{~cm} \\
(\mathrm{sec})\end{array}$ & $\begin{array}{c}286 \text { vs } 119 \\
(P=0.52)\end{array}$ & $\begin{array}{c}175 \text { vs } 119 \\
(P=0.08)\end{array}$ \\
\hline $\begin{array}{l}\text { Time to } 40 \mathrm{~cm} \\
(\mathrm{sec})\end{array}$ & $\begin{array}{c}341 \text { vs } 211 \\
(P=0.21)\end{array}$ & $\begin{array}{c}279 \text { vs } 211 \\
(P=0.31)\end{array}$ \\
\hline $\begin{array}{l}\text { Total examination } \\
\text { time (sec) }\end{array}$ & on $\begin{array}{c}530 \text { vs } 323 \\
(P=0.03)^{*}\end{array}$ & $\begin{array}{l}372 \text { vs } 323 \\
(P=0.41)\end{array}$ \\
\hline Directional errors & $\begin{array}{l}2.8 \text { vs } 1.6 \\
(P=0.26)\end{array}$ & $\begin{array}{l}2.8 \text { vs } 1.6 \\
(P=0.37)\end{array}$ \\
\hline $\begin{array}{l}\text { Time in red-out } \\
\text { (sec) }\end{array}$ & $\begin{array}{c}27 \text { vs } 14 \\
(\mathrm{P}=0.20)\end{array}$ & $\begin{array}{c}14 \text { vs } 20 \\
(P=0.49)\end{array}$ \\
\hline $\begin{array}{l}\text { Percentage of } \\
\text { colon visualized }\end{array}$ & $\begin{array}{c}55 \text { vs } 79 \\
(P=0.21)\end{array}$ & $\begin{array}{c}68 \text { vs } 79 \\
(P=0.35)\end{array}$ \\
\hline
\end{tabular}

*Statistically significant difference. 
Table 3. Resident Survey Responses to Using Virtual Reality Sigmoidoscopy Simulator.

\begin{tabular}{|c|c|c|c|c|c|}
\hline Experience With Simulator & $\begin{array}{c}\text { Strongly } \\
\text { Agree } \\
\%\end{array}$ & $\underset{\%}{\text { Agree }}$ & $\underset{\%}{\text { Neutral }}$ & $\begin{array}{l}\text { Disagree } \\
\%\end{array}$ & $\begin{array}{c}\text { Strongly } \\
\text { Disagree } \\
\%\end{array}$ \\
\hline Simulator resembles live sigmoidoscopy & 0 & 89 & 11 & 0 & 0 \\
\hline Graphics resembled actual colon & 22 & 67 & 11 & 0 & 0 \\
\hline Tactile feedback was similar to colon & 0 & 44 & 44 & 11 & 0 \\
\hline Learned hand-eye skills on simulator & 45 & 55 & 0 & 0 & 0 \\
\hline Learned more with more practice & 22 & 55 & 11 & 11 & 0 \\
\hline Gained confidence for live patient examination & 55 & 45 & 0 & 0 & 0 \\
\hline $\begin{array}{l}\text { Likely to perform in practice if simulator } \\
\text { available in training }\end{array}$ & 55 & 33 & 11 & 0 & 0 \\
\hline Tutorial component was helpful & 0 & 33 & 33 & 11 & 22 \\
\hline $\begin{array}{l}\text { Enhanced features on simulator would make } \\
\text { me skilled in flexible sigmoidoscopy }\end{array}$ & 44 & 44 & 11 & 0 & 0 \\
\hline
\end{tabular}

the most practice. This additional practice resulted in major improvements in their individual performance times and brought them closer to the group median for that phase of performance testing. In the second-phase pairing, the experimental group outperformed the control group, but the differences were not statistically significant (Table 2).

The quality of viewing the colon was assessed from the videotaped examinations to document the hand-eye skills of the examiners. An ability to perform this portion of the examination well usually reflects a coordinated use of the sigmoidoscope dials and torsion. These data are summarized in Table 1.

Patient response information revealed no perceived differences between the groups regarding pain, level of examiner confidence, or perceived duration of examination. Both patients had remarkably similar colons in that both reported substantial pain when the examiner tried to insert the sigmoidoscope beyond 42 to $45 \mathrm{~cm}$; otherwise, neither patient reported notable pain. Because each patient was to be subjected to numerous sequential examinations, it was decided there would be no attempts to pass the sigmoidoscope beyond $45 \mathrm{~cm}$.

The resident survey focused on three features of the virtual reality simulator and its effect on performance. Nine of the 10 residents responded to the survey; because the survey was anonymous, no attempt was made to single out the nonresponder. The questions addressed three aspects of the simulator technology as it related to the residents' experience during the trial. There was strong agreement among the residents that simulator training improved both their skills and their confidence in performing sigmoidoscopy. During a group discussion after the study and the surveys were completed, the residents strongly supported using the simulator to develop flexible sigmoidoscopy skills. The results of the survey are summarized in Table 3.

\section{Discussion}

This study is the first to attempt to measure quantitatively and qualitatively the impact of virtual reality simulation on live patient performance. During the past decade computer simulations have been introduced into medical training in the form of interactive software learning tools and anatomic instructional programs. Virtual reality technology advances the complexity and realism of a training simulator to new levels. Currently a limited number of simulations are available in research centers that are being developed into training models, and applying these simulations to training programs has been limited. ${ }^{12}$ Although the scope of this study was limited to assessing the effect of a virtual reality simulator on residents' sigmoidoscopy skills, this study describes a design model that could be duplicated to evaluate other simulators.

The Gastro-Sim virtual reality simulator offers several advantages in the training environment. During the study the primary investigator spent no more than 10 minutes orienting the entire group to the basic functions of the simulator; the remainder of the training was done by means of the interactive tutorial and the actual sigmoidoscopy prac- 
tice on the simulator. Several features of the simulator are notable. First, there are five different colons of varying complexity to examine, and many trainees commented that some colons in the simulator were more challenging than the live examinations. The simulator also provides tactile resistance feedback and emits sounds of pain if the trainee pushes the sigmoidoscope beyond predefined limits. The sigmoidoscope attached to the simulator is reconfigured with sensors to detect depth, movement of the dials, and rotation of the scope within the mannequin (Figure 2), and the external trappings give the trainee a feel for the actual work environment of a sigmoidoscopy room.

An additional feature of the simulator is its ability to conduct performance evaluations on the trainees by recording the examination time, a pain scale, the percentage of colon visualized, and the time in red-out. These features are still being developed and were not used in this study. Nevertheless, they could be used as a critical evaluation tool to predict trainee performance and need for further training.

The study design allowed us to asses the effect of training both before and after an initial live patient examination. To reduce the amount of colon variability, the residents were paired to examine the same patient sequentially during each phase of the trial. It was interesting that during the performance trials, after the initial pretest examination by the experienced sigmoidoscopist, there was little change in the patients' colon dynamics or difficulty encountered during the examination. The only exception occurred with the first trainee (in the experimental group), who examined her first patient shortly after a repeated enema. She encountered considerable spasm for about 5 minutes, which negatively affected her ability to visualize the lumen. Despite this difficulty, however, her performance was still superior to her matched control group trainee. This situation was avoided with subsequent examinations so another factor that could bias the results would not be introduced. Other potential biases, such as sex and level of residency training, were minimized when the residents were randomly assigned to their respective groups. In addition, none of the trainees had any previous exposure to sigmoidoscopy training.

Even though there were few trainees in each study group, performance times decreased with training on the simulator. Because there were so

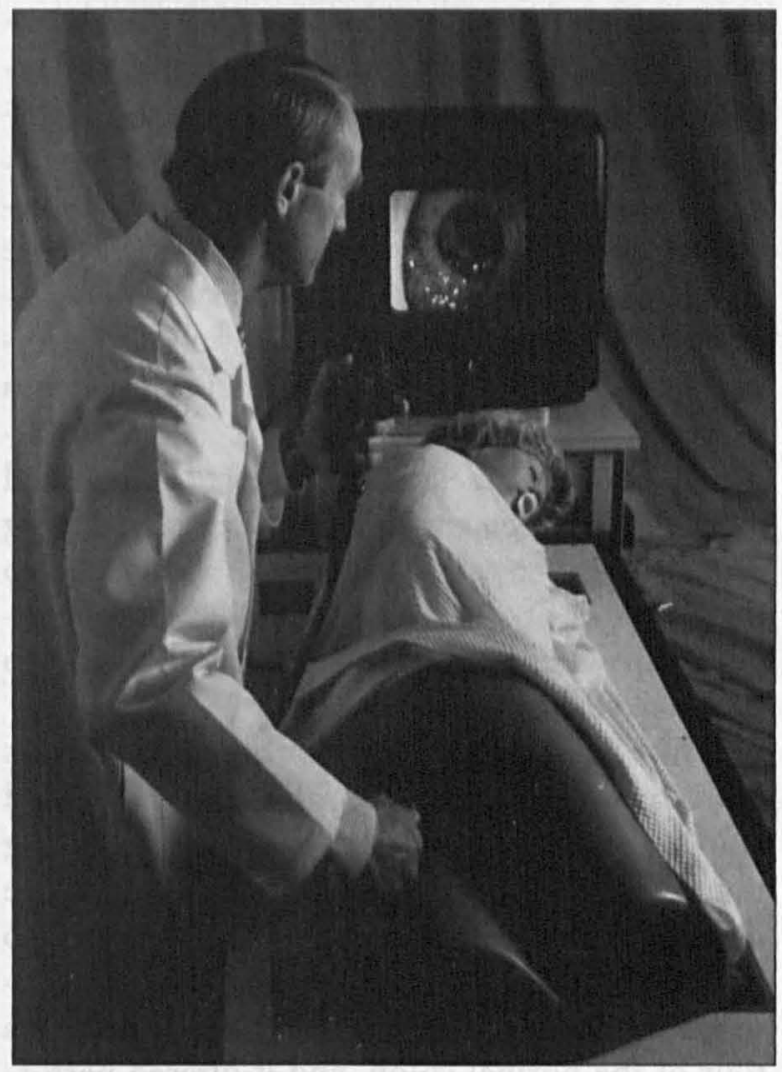

Figure 2. The Gastro-Sim flexible sigmoidoscope simulator.

few study participants, variations in hand-eye skills among the individual participants (thus a wider standard deviation) made it difficult for differences between groups to achieve statistical significance during the first phase of the trial. Nevertheless, those involved in training residents will recognize that the mean performance times of the experimental group were excellent. After further training on the simulator ( 6 to 10 hours), the experimental group was able to achieve greater homogeneity in their performance times and a significant reduction of the total time of their examinations when compared with the baseline established by the control group.

The effect of a previous live patient examination on performance times cannot be discounted entirely but did not appear to have a strong impact. That there were no significant differences in most performance areas within the experimental group between 5 hours and 6 to 10 hours of training indicates that previous exposure to a live patient examination does not substantially improve performance times.

Probably the most accurate gauge of improved hand-eye skills was the directional error measure- 
ments taken from the videotape of the examination. It was clear when a trainee, using trial and error with the sigmoidoscope dials, was having difficulty steering the sigmoidoscope into the lumen. Time spent in red-out also was noticeably different between those who were exposed to and those not exposed to simulator training, because the simulator allowed trainees to learn to retract the sigmoidoscope and make small directional changes toward where the lumen ought to be. Several residents who had trained on the simulator discovered independently the common practice of combining rotational torque with movement of a single dial to achieve most of the steering. A trainee usually requires specific instruction and demonstration to learn this skill.

This virtual reality simulator has many features not directly assessed during this trial that would enhance resident learning. Aside from allowing trainees to maneuver a sigmoidoscope through five different colon models of varying difficulty, it also provided a tutorial on the features of the sigmoidoscope and the use of the dials, the simulator gave a tour of the normal colon, and it offered performance feedback (induced pain level, time in redout, speed of examination, etc). Modifications for a future version of the simulator include practice in biopsy and in snaring and removing polyps; pathology recognition; and lesions to evaluate and, if appropriate, to biopsy or excise.

Flexible sigmoidoscopy training is offered in most US family practice and internal medicine residency training programs. On average, each resident might perform up to 20 examinations during training. 4,6,14 Although several authors have stated that 15 to 20 examinations are adequate to gain proficiency, $7,8,14$ the actual percentage of graduates performing flexible sigmoidoscopy after leaving residency is substantially lower than the percentage trained. In postgraduate surveys a reason often cited for not performing flexible sigmoidoscopy is the lack of skill level or lack of training. ${ }^{15}$ Clearly this discrepancy raises the question of whether the examination opportunities during training actually provide most graduates with the confidence and the skills to perform sigmoidoscopy. There is a great difference between being able to perform flexible sigmoidoscopy and doing so skillfully.

Another factor that influences a resident's ability to acquire sigmoidoscopy skills is the natural variation in hand-eye skills among individual students. Programs that are unable to provide more experiences for slower learners will not be able to guarantee the adequacy of their skills and future performance of sigmoidoscopy. Several studies refer to possible sex differences in learning that are not accommodated in the current training model. ${ }^{9}$

The residents' survey responses indicated they strongly agreed that the simulated training was valuable, especially for developing necessary handeye skills. They also believed that training on the simulator improved their confidence when performing sigmoidoscopy and would enhance the likelihood of their mastering the skill later in practice. A strong indicator that the residents valued this training device was their willingness to commit to the necessary hours of using the simulator during the study. All residents voluntarily trained on the simulator on their own time despite normal work schedules.

At present the only options for trainees who have difficulty coordinating sigmoidoscopy movements are either to perform more examinations during training or to continue to have supervised examinations in practice until the skill can be acquired. The latter option is difficult for most physicians to arrange. The flexible sigmoidoscopy simulator allows for individual feedback on performance, performance tracking with time, and unlimited practice. Finally, trainees have the option to come back to the simulator throughout their training to work on their skills.

Virtual reality in medical training is an emerging technology. Described here is an experimental model to evaluate a sigmoidoscopy training device, not only for the hand-eye skills required by the examiner, but also for the desired end result-procedure performance on a live patient: Using such technologic advances as virtual reality simulations might make it possible not only to accelerate learning procedural skills but also to maintain these skills when they are performed infrequently in daily practice. A simulator can also provide a comprehensive training curriculum, which is not currently available in many programs. More important, the ability to train residents to a high level of competence in flexible sigmoidoscopy will translate into better physician compliance with the current screening guidelines and improve patient comfort and trust in their physician's skills. ${ }^{1,5}$ 


\section{References}

1. Schoen RE, Weissfeld JL, Kuller LH. Sigmoidoscopy use among primary care physicians. Prev Med 1995;24:249-54.

2. Rodney WM, Beaber RJ, Johnson R, Quan M. Physician compliance with colorectal cancer screening (1978-1983): impact of flexible sigmoidoscopy. J Fam Pract 1985;20:265-9.

3. Johnson RA, Quan M, Rodney WM. Continued assessment of flexible sigmoidoscopy in a family practice residency.J Fam Pract 1984;18:723-7.

4. Lewan RB, Caskin WN, Sharon MW, Greenlaw RL, Frakes JT, Vidican DE. A supervised training program in flexible sigmoidoscopy: evaluating skills from residency training to clinical practice. Fam Med 1989;21:25-9.

5. Crump WJ, Phelps TK. Teaching lower gastrointestinal endoscopy: a comparison of family medicine and internal medicine residencies. J Am Board Fam Pract 1991;4:1-4.

6. Schertz RD, Baskin WN, Frakes JT. Flexible fiberoptic sigmoidoscopy training for primary care physicians: results of a 5-year experience. Gastrointest Endosc 1989;35:316-20.

7. Rodriguez-Bigas MA, Palmer M, Petrelli NJ.
Problems encountered in teaching the use of the 65 $\mathrm{cm}$ flexible sigmoidoscope in a surgical oncology training program. J Cancer Educ 1993;8:2 13-16.

8. Brill JR, Baumgardner DJ. Establishing proficiency in flexible sigmoidoscopy in a family practice residency program. Fam Med 1997;29:580-3.

9. Saad JA, Pirie P, Sprafka JM. Relationship between flexible sigmoidoscopy training during residency and the subsequent sigmoidoscopy performance in practice. Fam Med 1994;26:250-3.

10. Satava RM. Medical applications of virtual reality. J Med Syst 1995;19:275-80.

11. Ziegler R, Fischer G, Muller W, Gobel M. Virtual reality arthroscopy training simulator. Comput Biol Med 1995;25:193-203.

12. Burt $\mathrm{DE}$. Virtual reality in anaethesia. Br J Anaesth 1995;75:472-80.

13. Hon D. Expert system simulator for modeling realistic internal environments and performance. United States patent no 4,407,973.13 March 1990.

14. DiSario JA, Sanowski RA. Sigmoidoscopy training for nurses and resident physicians. Gastrointest Endosc 1993;39:29-32.

15. al Turk M, Susman J. Perceived core procedural skills for Nebraska family physicians. Fam Pract Res J 1992;12:297-303. 